\title{
Associação entre fatores preditores e grau de úlcera de pressão em hospital terciário do SUS
}

\author{
Braz, M.S.; Sobreira, M.S.; Cappellari, N.F.; Mengue, C.S.; Seidl, D.S.; Braga \\ Junior, R.V.;
}

Apresentador: Monica Silva Braz

\section{Resumo}

Introdução: Úlceras de pressão (UP) são lesões localizadas na pele e tecidos adjacentes decorrentes de isquemia tecidual provocada por pressão e/ou forças de cisalhamento. Estas lesões usualmente se desenvolvem sobre proeminências ósseas como na região sacral e calcanhares. Este estudo objetiva avaliar o perfil demográfico de pacientes portadores de UP em um hospital público terciário de Porto Alegre e a associação entre os fatores de risco para UP e a gravidade das lesões. Método: Estudo transversal descritivo de grupo de pacientes adultos e idosos $(n=71)$ portadores de UP, com coleta dos dados realizada através de exame físico e revisão de dados clínicos e laboratoriais dos prontuários, e posterior análise estatística por SPSS no período de dezembro de 2013 a janeiro de 2014 no Hospital Nossa Senhora da Conceição de Porto Alegre/RS. Resultados: O perfil epidemiológico encontrado neste estudo (pacientes com UP) revela predominância do sexo masculino (58\%), presença de infecção na escara em $25 \%$ dos casos, idade média de 67 anos (variando de 19 a 87 anos), sendo 90,5\% com restrição de mobilidade, $25,4 \%$ diabéticos e $11 \%$ usuários crônicos de corticóide. O nível médio de albumina sérica foi de 2,6 g/dl (valor de referência: 3,5-5,0 g/dl). Já os valores médios de IMC ficaram dentro do normal e a dosagem sérica de magnésio apresentou valores no limite inferior da normalidade. Encontrou-se associação estatisticamente significativa ( $p$ ? 0,05) entre a severidade das UP, presença de infecção e o sexo masculino. Não foi observada associação significativa $(\mathrm{p}>0,05)$ entre o grau da UP e as demais variáveis analisadas (tempo de internação na Emergência do Hospital, limitação da mobilidade, idade, índice de massa corporal (IMC), albumina sérica, magnésio sérico, presença de diabetes mellitus, e uso crônico de glicocorticóides). Conclusões: As UP são uma importante causa de morbimortalidade. Dentre os fatores predisponentes de UP modificáveis, destaca-se o estado nutricional do paciente, que contribui de forma significativa tanto para o aparecimento como para a evolução das UP. O presente estudo demonstrou que os fatores de risco para o surgimento de UP estabelecidos na literatura não apresentam relação com a gravidade das úlceras, ao contrário de sexo masculino e de presença de infecção da ferida. Além disso, permitiu uma melhor caracterização do perfil dos pacientes acometidos por UP neste Hospital.

\section{Referência:}

Braz, M.S.; Sobreira, M.S.; Cappellari, N.F.; Mengue, C.S.; Seidl, D.S.; Braga Junior, R.V.;. Associação entre fatores preditores e grau de úlcera de pressão em hospital terciário do SUS. In: II Congresso Brasileiro de Medicina Hospitalar - II CBMH [= Blucher Medical Proceedings, vol.1, num.5] São Paulo: Editora Blucher, 2014. p.46

DOI 10.5151/medpro-II-cbmh-041 